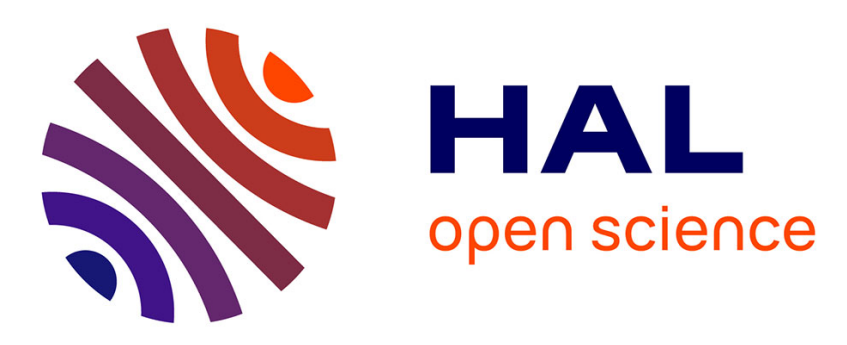

\title{
Measuring Stressors Among Adolescents: Validation of the Positive and Negative Adolescent Life Experiences Scale
}

Fernando Núñez-Regueiro, Isabelle Archambault, Pascal Bressoux, Cécile Nurra

\section{- To cite this version:}

Fernando Núñez-Regueiro, Isabelle Archambault, Pascal Bressoux, Cécile Nurra. Measuring Stressors Among Adolescents: Validation of the Positive and Negative Adolescent Life Experiences Scale. Journal of Psychoeducational Assessment, 2021, pp.073428292110277. 10.1177/07342829211027751 . hal-03343263

\section{HAL Id: hal-03343263 \\ https://hal.science/hal-03343263}

Submitted on 21 Oct 2021

HAL is a multi-disciplinary open access archive for the deposit and dissemination of scientific research documents, whether they are published or not. The documents may come from teaching and research institutions in France or abroad, or from public or private research centers.
L'archive ouverte pluridisciplinaire HAL, est destinée au dépôt et à la diffusion de documents scientifiques de niveau recherche, publiés ou non, émanant des établissements d'enseignement et de recherche français ou étrangers, des laboratoires publics ou privés. 


\title{
Measuring Stressors Among Adolescents: Validation of the Positive and Negative Adolescent Life Experiences Scale
}

\author{
Fernando Núñez-Regueiro' ${ }^{\circledR}$, Isabelle \\ Archambault ${ }^{2}$, Pascal Bressoux', and Cécile \\ Nurra'
}

\begin{abstract}
This article develops and validates the Positive and Negative Adolescent Life Experiences (PANALE) scale, a II-item tool that enables researchers to measure adolescent stressors in a more valid and efficient manner than existing adolescent stressors scales. The PANALE presents good psychometric qualities, in terms of construct validity (factorial structure, measurement invariance, and composite reliability) and concurrent validity with regard to eustress and distress symptoms in a French sample of high school adolescents $(N=1513)$. Overall, the PANALE provides a viable alternative to existing methods for conducting quantitative research on adolescent stress processes, notably those related to school disengagement and dropout processes.
\end{abstract}

\section{Keywords}

stressors, adolescence, scale validation, measurement invariance, binary indicators

\section{Introduction}

Stressors can be defined as life experiences disrupting the homeostatic fit between the individual and her or his environment, thus generating a psychophysiological response to overcome, cope with, or even outgrow the lack of fit (Aldwin, 2007; Compas et al., 1987; Pearlin \& Bierman, 2013; Wheaton et al., 2013). Although reviews concur that being exposed to stressors during adolescence increases the risk of developing psychological or behavioral problems (Compas, 1987; Grant et al., 2004) and, in particular, of disengaging from school and dropping out (Dupéré et al., 2015, 2018), research on the subject has been plagued by a lack of unity with regard to how adolescent stressors are measured. As reported in a recent review (Núñez-Regueiro et al., in press), at least 56 different measurement methods have been used across empirical studies, but none has stood out as a viable method for conducting quantitative research. First, existing tools are often

\footnotetext{
'Univ. Grenoble Alpes, LaRAC, France

${ }^{2}$ Université de Montréal, Montreal, QC, Canada

Corresponding Author:

Fernando Núñez-Regueiro, Laboratoire de Recherche sur les Apprentissages en Contexte, Université Grenoble Alpes, 125I Avenue centrale, BP 47, 38040 Grenoble Cedex 9, France.

Email: fernando.nunez-regueiro@univ-grenoble-alpes.fr
} 
based on intensive methods requiring substantive investment on behalf of participants and researchers, thus increasing research costs and limiting feasibility. Second, the measurement invariance of the scales across groups of adolescents (e.g., gender, and socioeconomic background) or across time has yet to be demonstrated, despite this being a prerequisite for investigating group differences in exposure to stress or its impact on development.

The present study develops and validates the Positive and Negative Adolescent Life Experiences (PANALE), a short scale assessing stressful life events among adolescents across multiple domains. After a brief overview of the existing stressors scales, we describe the development of PANALE items for content validity and report evidence of its construct validity and concurrent validity with regard to eustress and distress indicators $(N=1513)$. We argue that the PANALE offers a short and more viable solution to the measurement of stressors that affect adolescents' development and functioning at school, including adolescents from specific groups (i.e., as a function of gender, SES, and dropout status).

\section{Strengths and Limitations of Existing Stressors Scales}

Over 50 scales have been developed in more than 10 countries in the last decades to measure child and adolescent stressors. These tools present a number of strengths and limitations (for details, see Núñez-Regueiro et al., in press). On the one hand, most scales show good content validity by covering multiple domains of life (e.g., peers, family, school, and neighborhood) representing the "universe of stressors" or the process of "stress proliferation" (Pearlin \& Bierman, 2013; Wheaton et al., 2013). Here, the predominant approach has been to measure negative stressors (e.g., parent getting sick and being teased by peers), but a few scales have also measured positively valenced stressors (e.g., made a new friend; Kanner et al., 1987; Masten et al., 1994; Newcomb et al., 1981; Swearingen \& Cohen, 1985). Evidence of the reliability of these scales has also been demonstrated as most existing tools present good internal consistency (moderate to high Cronbach's $\alpha$ or testretest correlations) or interrater consistency (moderate to high Cohen's $\kappa$, intraclass correlations, or interrater correlations; Núñez-Regueiro et al., in press; Berden et al., 1990; Cheng \& Li, 2010; Compas et al., 1987; Williamson et al., 2003; Wu \& Lam, 1993). Finally, most scales have shown positive associations with distress indicators such as anxiety and depressive symptoms and conduct disorder at school or in general $\left(.17<r_{\text {median }}<.38\right)$ and negative associations with eustress indicators, such as school grades, general self-worth or self-confidence, and selfregulation $\left(-.07>r_{\text {median }}>-.17\right.$; Núñez-Regueiro et al., in press). Such correlations attest to the criterion validity of scales, by defining stressors as undermining positive development or fostering negative development (Aldwin, 2007; Turner \& Wheaton, 1997). Importantly, current evidence also suggests that there are no substantial differences in the quality of stressors scores produced by different methods, such as interview or checklists (Lewinsohn et al., 2003; Swearingen \& Cohen, 1985; Wagner et al., 2006; Williamson et al., 2003). Moreover, there do not seem to be differences between stressor scores when assessing stressors in terms of intensity (i.e., degree of strength or severity associated with the occurrence of a stressor), frequency (i.e., degree of occurrence or chronicity of a stressor), or independence (i.e., degree of control over the occurrence of a stressor; Compas et al., 1987; Swearingen \& Cohen, 1985; Turner \& Wheaton, 1997; Wu \& Lam, 1993). The valence of stressors (i.e., the distinction of positive and negative stressors) and their occurrence (i.e., their contribution to the total number of stressors experienced) appear to be more relevant dimensions to consider (Kanner et al., 1987; Newcomb et al., 1981; Sarason et al., 1978; Swearingen \& Cohen, 1985).

On the other hand, existing stressors scales present two major limitations (Núñez-Regueiro et al., in press). First, some methods require substantial investment on behalf of participants by asking them to answer checklists assessing sometimes over hundreds of events or, alternatively, hour-long individual interviews (Compas et al., 1987; Dupéré et al., 2017; Swearingen \& Cohen, 
1985; Williamson et al., 2003). Such intensive techniques may generate poor-quality data in the form of satisficing behavior or missing data (Dupéré et al., 2017; Galesic \& Bosnjak, 2009; Gibson \& Bowling, 2020) and limit the investigation of other variables relevant to the stress processes as a whole, such as personal or social resources or eustress or distress symptoms.

Second, existing scales have been validated only among adolescents from the general population. For instance, none of them but one (Cheng \& Li, 2010) has been proofed for measurement invariance across subgroups in the population or across time. This limits the validity of studies that have investigated group differences in stress exposure or the relationships between exposure to stress and other outcome variables among populations more likely to experience stress, like girls, adolescents from low-SES families or school dropouts (Dupéré et al., 2018; Kanner et al., 1987; Kohn \& Milrose, 1993; Newcomb et al., 1981). To produce scores that can be validly used to test group differences or to estimate regression parameters and correlations, stressors scales need to show "strong invariance" over groups of interest or over time, that is, invariance in the loadings of the items that are summed up to produce the stress score (Brown, 2015; Vandenberg \& Lance, 2000). Although Cheng and Li's (2010) “Adolescent Stress Index" was shown to be strongly invariant over time, across two time points, this scale suffers from being quite long (i.e., checklist of 42 stressors), thus falling to the first shortcoming of stressors scales, namely, a limited practical feasibility. Moreover, the scale has not been shown to be invariant across subgroups of adolescents. The development of a measure that could be used validly among different groups of adolescents and over time is thus warranted.

\section{Present Study}

The present study validates the PANALE scale. In terms of construct validity, we pay special attention to establishing the factorial structure of the scale as an indicator of an unobserved latent factor (i.e., a stress universe or stress proliferation factor; Pearlin \& Bierman, 2013; Wheaton et al., 2013 ) as well as its measurement invariance over time and relevant subgroups in the population (gender, SES, and school dropout status). In terms of concurrent validity, we assess the associations of PANALE scores with multiple indicators of eustress and distress. We validate the PANALE using occurrence ratings (i.e., total occurrences of positive or negative events), while also considering an augmented form of rating for comparison with the literature (i.e., total perceived intensity of positive or negative events). Based on previous evidence (Swearingen \& Cohen, 1985; Wu \& Lam, 1993), we expect the two forms of rating to show equivalent criterion validity with respect to distress or eustress indicators.

\section{Developing PANALE Items: An Approach Based on Categories of Stressors}

Our goal in developing the PANALE was to obtain a short scale of exposure to stress by focusing on general categories of stressors. This approach differs from that privileged in the literature, where most scales measure specific stressors that belong to a common category. For example, instead of asking adolescents about specific health issues (e.g., injury or illness, accident, and serious injury; Masten et al., 1994) or specific kinds of conflicts (e.g., conflicts with parents regarding mutual trust, rules at home, punishments, and choice of friends; Bobo et al., 1986), the PANALE asks adolescents to report if they experienced "rather serious problems," or if they had "one or several arguments" with their parents (cf. items 6 and 7, Table 1). By privileging this categorical approach, we were able to obtain a short yet comprehensive set of 11 items reported in Table 1. 
Table I. PANALE Items (English Version).

Event in the last 3 months

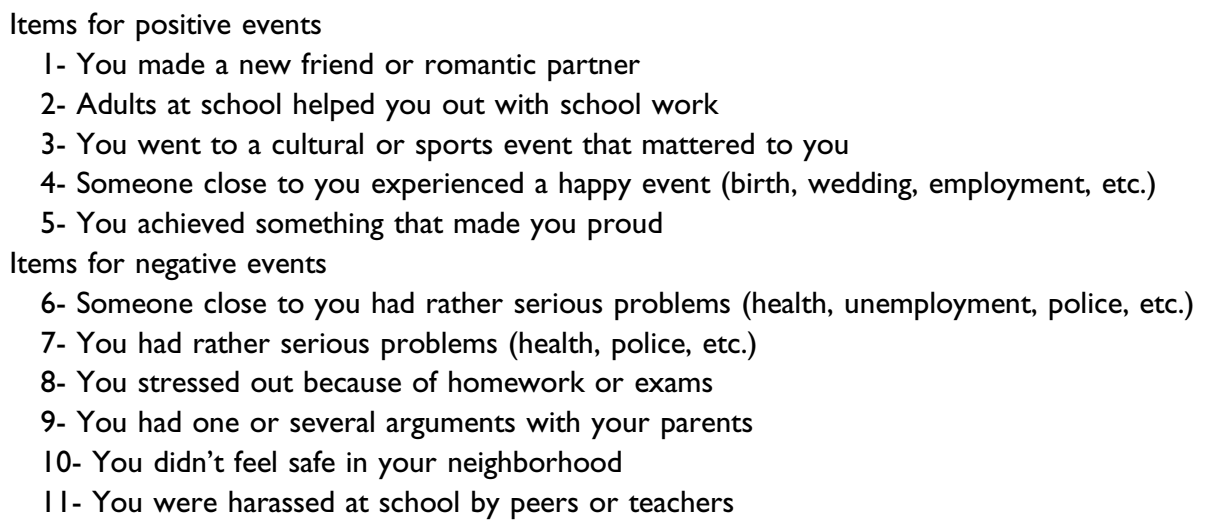

Note. Items translated from French (cf. original items in Supplementary Appendix A). Items are assessed on 4-point Likert scales (see "Method").

To obtain a satisfactory coverage of adolescent stressors across multiple domains of life, the PANALE items were developed based on the most salient categories identified in a text analysis of self-reported stressors among high school adolescents (Núñez-Regueiro \& Núñez-Regueiro, 2021). Specifically, items for positive stressors cover romantic and friendship experiences (item 1), good relationships with teachers and receiving help (item 2), leisure activities (item 3), spending good time with family and birth in the family (item 4), and personal accomplishments (item 5; Table 1). For negative stressors, the scale also covers personal welfare (item 7) and significant others' welfare (item 6), social conflicts with parents (item 9), feelings of insecurity in the neighborhood (item 10), and problems at school in the form of school harassment by peers or teachers and school pressure (items 8 and 11; Table 1). The scale initially contained an additional item accounting for parental separation or divorce, but this item was removed because its static nature undermined the (dynamic) measurement of cumulative stress (removed item = "Your parents separated").

In sum, a comparison of the PANALE items with the potential adolescent stressors identified in the literature suggests that the scale has good content validity. Based on our text analysis (NúñezRegueiro \& Núñez-Regueiro, 2021), only one major category of negative stressors appears to be missing out, namely, romantic and friendship issues. This omission limits the content validity of the scale. Yet, the impact of this omission appears negligible given the satisfactory criterion validity of the scale, as reported hereafter. For greater content validity, a refined version of the PANALE should, however, include a supplementary item for negative stressors of this kind (e.g., an additional item 12, "You broke up or had a strong argument with your best friend or romantic partner").

\section{Validation of the PANALE Scale}

\section{Method}

Sample. Participants were French students in their second and third year of high school, surveyed in the context of a study on school dropout $(N=1513)$. Equivalence tests show that the study sample is equivalent to the national population at the 5\% significance level concerning gender, father SES, academic ability, and grade retention or dropout during high school and presents 
a mild overrepresentation of vocational students in the occupational sector of production (vs. services; for details, see Supplementary Appendix B).

Procedure. Students voluntarily completed an online questionnaire (111 items) comprising the PANALE scale on five measurements points (T1 to T5), that is, once every trimester except the last trimester for which missing data were too large. Instructions asked students to rate each PANALE item presented in Table 1 for its occurrence in the last 3 months. This time frame was chosen to obtain measures of exposure to stress that could be situated within each trimester.

\section{Measures}

PANALE Scores. The rating scheme for the PANALE includes measures of the occurrence and of the perceived intensity associated with each stressor. The 4-point graduation scale for negative events assesses whether the event occurred and to what extent it hurt the subject $(1=$ "No," $2=$ "Yes, but it didn't hurt much," 3 = "Yes, and it hurt me," and 4 = "Yes, and it hurt me very much"), whereas the scale for positive events assesses whether the event occurred and to what extent it brought about relief $(1=$ "No," 2 = "Yes, but it didn't really made me feel good," 3 = "Yes, and it made me feel good," and $4=$ "Yes, and it made me feel really good"). Two kinds of PANALE scores are compared. The first one ignores the perceived intensity of each PANALE item and encodes them as binary $(1=$ "No" and $2=$ "Yes"), to obtain measures of total occurrences for positive events $\left(\right.$ Occur $\left._{\text {positive }}\right)$ and negative events $\left(\right.$ Occur $\left._{\text {negative }}\right)$. This is our privileged rating system, for which psychometric analyses are presented next. The second form of rating computes sum scores based on the perceived intensity of positive events (Intensity positive $_{\text {) }}$ and negative events

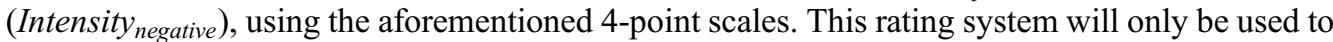
compare the concurrent validity of both kinds of ratings.

Eustress and Distress. In order to assess the concurrent validity of the PANALE scores, distress and eustress indicators were measured using self-reported data (items adapted to the French school context, rated on 5-point scales) and administrative data from schools (for school grades and absences). In terms of eustress, we measured self-esteem (five items, $\bar{\omega}=.920$; Harter, 1988), school liking (three items, $\bar{\omega}=.774$; Janosz et al., 2007), concentration in class (seven items, $\bar{\omega}=.946$; Skinner et al., 2008), and grade point average as rated for each trimester on school records (21 point scale). In terms of distress, we measured general anxiety (six items, $\bar{\omega}=.951$; Untas et al., 2009), misbehavior at school (four items, $\bar{\omega}=.948$; Finn et al., 2008), social deviance (three items, $\bar{\omega}=.896$; Finn et al., 2008), dropout intention (one item rated on a 100-point scale, "What are the chances that you decide to quit school before obtaining a diploma?"), and school absenteeism defined as the count of daily absences and tardiness as registered in school databases for each trimester. The above variables include most attitudinal and behavioral indicators used in stressors scales validation studies (Núñez-Regueiro et al., in press) and can therefore be considered large in scope.

Invariance Groups. The variables used to test the measurement invariance of the PANALE over subgroups of adolescents included gender $(0=$ female adolescent, $1=$ male adolescent; administrative data), father SES ( $0=$ low/intermediate, $1=$ high/very high; self-reported $)$ and high school dropout status $(1=$ yes, $0=$ no; administrative data).

\section{Analytic Strategy}

Exploratory Factor Analyses. In order to determine the most plausible number of latent factors explaining the variance in PANALE items, EFAs were conducted. Methods in this area are numerous, but those based on Velicer's minimum average partial correlations or MAP (i.e., retain factors with minimum partial correlations) and parallel analyses or PA appear most effective (i.e., retain factors for which the eigenvalue is situated above a simulated eigenvalue; Fabrigar et al., 1999). Monte Carlo simulations conducted by Garrido and his colleagues (Garrido et al., 2011, 
2013, 2016) have shown that MAP and PA methods can provide valid evidence in the binary case when using tetrachoric correlations and a principal component extraction method. This is especially true in conditions that, we shall see, are similar to ours such as a large sample size $(N>$ $500)$, high factor loadings ( $\geq .55)$, multiple variables per factor $(\geq 4)$, and low number of factors $(\leq 2$; Garrido et al., 2011, 2013). We therefore implemented their methodology for positive and negative PANALE items separately (cf. Table 1) using the psych package on R (Revelle, 2019).

Confirmatory Factor Analyses. The next step in validating the PANALE was to evaluate the scale in terms of measurement invariance (Vandenberg \& Lance, 2000; Wu \& Estabrook, 2016). According to EFA results presented hereafter, the measurement model consisted in a single latent factor (i.e., exposure to stressors) loading on binary indicators (i.e., PANALE items). We assessed the invariance of the model across groups (e.g., gender, SES, and dropout status) or occasions (five waves), first by imposing the same configuration of factor indicators (i.e., configural model), then by constraining model parameters to be invariant as well in terms of thresholds, intercepts, and loadings (i.e., strong invariance), and, lastly, in terms of variances as well (i.e., strict invariance). Models were implemented following procedures specific to measurement models for binary data (Wu \& Estabrook, 2016; for details, see Supplementary Appendix C). CFA parameters and fit indices were estimated on the R package lavaan (Rosseel, 2012) using mean- and variancecorrected diagonal weighted least squares (WLSMV), a recommended estimator for ordinal data with less than five categories (Rhemtulla et al., 2012).

Fit indices were used to evaluate CFA models (overall fit) and invariance constraints (difference tests). Monte Carlo simulations have shown that, in large sample such as ours $(N \geq 1000)$, chi-square statistics tend to produce inflated Type I errors (i.e., incorrectly rejecting well-specified or non-invariant models) when applied to CFA models for asymmetric ordinal or binary data using the WLSMV estimator (Bandalos, 2014; French \& Finch, 2006; Green et al., 1997; Kite et al., 2018; Sass et al., 2014). Instead, we decided to consider fit indices for which Type I errors and power to detect non-negligible invariance have been reported to be optimal in large sample CFAs for ordinal data (Sass et al., 2014) and continuous data (Jorgensen et al., 2018). Following these simulations studies, we will consider indices $\mathrm{CFI}>.95, \mathrm{Mc}>.90$, and $\mathrm{RMSEA}<.06$ as providing evidence of satisfactory overall fit (Jorgensen et al., 2018) and differences $\triangle \mathrm{CFI} \geq-.002$, $\triangle \mathrm{TLI} \geq-.001, \triangle \mathrm{Mc} \geq-.007$, and $\triangle \mathrm{RMSEA} \leq .007$ as providing evidence of measurement invariance (Jorgensen et al., 2018; Sass et al., 2014).

Internal Consistency. The internal consistency or composite reliability of the PANALE scores was estimated for each measurement occasion using tetrachoric correlations for binary data and a correlated errors structure, using the "omega" function of the R package psych (Revelle, 2019). This indicator was preferred over Cronbach's alpha, which may be inappropriate for binary data and in cases with unequal loadings across factor indicators (McNeish, 2018) as was the case for the PANALE.

Concurrent Validity. Aligning with the majority of validation studies in life stress research, concurrent validity was assessed by estimating Pearson product moment correlations between PANALE scores and distress and eustress criteria. A series of chi-square tests showed that the size of correlations did not differ across occasions, both for ratings based on total occurrences $\left[\Delta \chi_{72}^{2}=\right.$ $85.5, p=.131]$ and total intensity $\left[\Delta \chi_{72}^{2}=88.2, p=.940\right]$. We therefore report correlations from the invariant correlation models. To assess differences between rating systems, we computed average correlations across measurements and performed a Fisher test of the difference in effect sizes for each average correlation (PANALE occurrences vs. PANALE intensity). The correlations and difference tests were estimated on Mplus and R CRAN, respectively (Hallquist \& Wiley, 2018; Muthén \& Muthén, 2012; R Core Team, 2016).

Missing Data. Response rates on the questionnaire containing the PANALE was modest for each measurement occasion (from $41 \%$ to $58 \%$ ) but satisfactory overall, with $86 \%$ of students with responses on at least two occasions. By using a pairwise deletion strategy, our CFA models 
Table 2. MAP, Eigenvalues, and Internal Consistency of Latent Factors of the PANALE Across Measurement Occasions.

\begin{tabular}{|c|c|c|c|c|c|c|c|}
\hline & \multicolumn{3}{|c|}{ MAP } & \multicolumn{3}{|c|}{ Observed (Simulated) eigenvalues } & \multirow[b]{2}{*}{ Omega total } \\
\hline & I Factor & 2 Factors & 3 Factors & Factor I & Factor 2 & Factor 3 & \\
\hline \multicolumn{8}{|c|}{ Positive items } \\
\hline TI & .064 & .188 & .473 & $2.922(1.073)$ & $.711(1.032)$ & $.528(.999)$ & .857 \\
\hline $\mathrm{T} 2$ & .067 & .204 & .463 & $3.042(1.073)$ & $.672(1.032)$ & $.501(1.000)$ & .871 \\
\hline T3 & .071 & .180 & .432 & $3.043(1.073)$ & $.635(1.034)$ & $.490(.999)$ & .871 \\
\hline $\mathrm{T} 4$ & .073 & .184 & .402 & $2.999(1.071)$ & $.697(1.031)$ & $.504(1.000)$ & .866 \\
\hline T5 & .067 & .214 & .394 & $3.133(1.070)$ & $.636(1.032)$ & $.474(1.000)$ & .880 \\
\hline \multicolumn{8}{|c|}{ Negative items } \\
\hline TI & .097 & .143 & .230 & $3.832(1.085)$ & $.820(1.046)$ & $.543(1.013)$ & .965 \\
\hline $\mathrm{T} 2$ & .068 & .163 & .242 & $4.047(1.085)$ & $.714(1.046)$ & $.496(1.015)$ & .969 \\
\hline T3 & .104 & .225 & .247 & $4.265(1.085)$ & $.613(1.046)$ & $.529(1.014)$ & .977 \\
\hline T4 & .088 & .171 & .234 & $4.153(1.088)$ & $.78 I(1.045)$ & $.438(1.012)$ & .975 \\
\hline T5 & .103 & .212 & .246 & $4.195(1.086)$ & $.667(1.046)$ & $.543(1.013)$ & .976 \\
\hline
\end{tabular}

Note. $N=572-824$ high school students, depending on occasions. MAP = minimum average partial correlations.

account for most of the sample (14\%-16\% missing data, depending on the multigroup analysis; see Supplementary Appendix D). This strategy could not be implemented for EFAs or for internal consistency indices, which were conducted separately for each occasion but provided coherent results across occasions. Concerning correlations, we included auxiliary variables that explained most of the missingness on each occasion [i.e., age, gender, father SES, grade retention before high school, academic ability, curricular track, first year grades, and absenteeism; Mean $($ NagelkerkeR2) $=.725]$, following the saturated approach described by Graham (2003) and its automatic implementation on Mplus via the "AUXILIARY" option (Muthén \& Muthén, 2012). By applying this technique, our correlational analyses are based on $99 \%$ of the sample $(n=1512)$ and are likely robust to missing data.

\section{Results}

\section{Factorial Structure of the PANALE}

Across all occasions, the EFAs suggested the existence of a single latent factor, both for positive and negative PANALE items (cf. Table 2). Velicer's MAP criterion (Garrido et al., 2011) was obtained when a single principal component was extracted. Likewise, the parallel analyses showed that the eigenvalues associated with the first principal component was higher than its simulated counterpart, whereas the reverse was true for the following principal components. This suggested that only the first component retained non-random variance across PANALE items (Garrido et al., 2013). In sum, these results strongly suggested that the PANALE scale was driven by a single latent factor.

\section{Measurement Invariance and Internal Consistency}

According to the chosen cutoff values for fit indices (CFI > .95, Mc > .90, RMSEA < .06; Jorgensen et al., 2018), all measurement models for the PANALE presented satisfactory fit (cf. Tables 3-6). This was true for both configural models and models constrained to be strongly or strictly invariant across occasions or groups (gender, SES, and dropout status). Moreover, all 
Table 3. Fit Indices (Differences in Fit Indices) of PANALE Models With Increasing Invariance Constraints Across Measurements.

\begin{tabular}{|c|c|c|c|c|c|c|}
\hline $\begin{array}{l}\text { Invariance } \\
\text { constraints }\end{array}$ & $\chi^{2}\left(\triangle \chi^{2}\right)$ & $\begin{array}{c}\mathrm{DF} \\
(\triangle \mathrm{DF})\end{array}$ & $\mathrm{CFI}(\triangle \mathrm{CFI})$ & TLI $(\triangle T L I)$ & $\operatorname{Mc}(\triangle M c)$ & $\begin{array}{c}\text { RMSEA } \\
(\triangle \text { RMSEA })\end{array}$ \\
\hline \multicolumn{7}{|c|}{ Positive events } \\
\hline I & 218.0 & 215 & .999 & .999 & 1.023 & .003 \\
\hline 2 & $255.1 \dagger\left(45.5^{* * *}\right)$ & $227(12)$ & $.995(-.004)^{\mathrm{a}}$ & $.993(-.006)^{\mathrm{a}}$ & $1.016(-.007)$ & $.010(.007)$ \\
\hline 3 & $268.8(I 7.4)$ & $247(20)$ & $.996(.001)$ & $.995(.002)$ & $1.015(-.001)$ & $.008(-.002)$ \\
\hline \multicolumn{7}{|c|}{ Negative events } \\
\hline I & $626.4^{* * *}$ & 335 & .978 & .972 & .930 & .026 \\
\hline 2 & $656.0^{* * *}\left(36.7^{* *}\right)$ & $351(16)$ & $.977(-.001)$ & $.972(<.00 \mathrm{I})$ & $.929(-.001)$ & $.026(<.001)$ \\
\hline 3 & 657.9*** (29.2) & $375(24)$ & $.979(.002)$ & $.975(.003)$ & $.922(-.007)$ & $.024(-.002)$ \\
\hline
\end{tabular}

Note. See Supplementary Appendix D for more details on model specifications. Models in bold characters are retained as providing the best fit. ${ }^{\dagger} p<.10,{ }^{* *} p<.01,{ }^{* * *} p<.00 \mathrm{I} . \mathrm{I}=$ configural invariance; 2 = strong invariance (unique thresholds, intercepts, and loadings); 3 = strict invariance (unique thresholds, intercepts, loadings, and variances). DF $=$ degrees of freedom; CFI = confirmatory fit index; TLI = Tucker-Lewis index; Mc = McDonald's centrality index; RMSEA = root mean squared error of approximation.

${ }^{\mathrm{a}}$ Evidence of measurement variance: $\triangle \mathrm{CFI}<-.002, \triangle \mathrm{TLI}<-.00 \mathrm{I}$.

Table 4. Fit Indices (Differences in Fit Indices) of PANALE Models With Increasing Invariance Constraints Across Gender Groups.

\begin{tabular}{|c|c|c|c|c|c|c|}
\hline $\begin{array}{l}\text { Invariance } \\
\text { constraints }\end{array}$ & $\chi^{2}\left(\Delta \chi^{2}\right)$ & $\begin{array}{c}\mathrm{DF} \\
(\triangle \mathrm{DF})\end{array}$ & $\mathrm{CFI}(\triangle \mathrm{CFI})$ & $\mathrm{TLI}(\triangle \mathrm{TLI})$ & $M c(\triangle M c)$ & $\begin{array}{c}\text { RMSEA } \\
(\triangle \mathrm{RMSEA})\end{array}$ \\
\hline \multicolumn{7}{|c|}{ Positive events } \\
\hline I & 439.4 & 430 & .998 & .998 & 1.045 & .006 \\
\hline 2 & $472.5\left(37.7^{* * *}\right)$ & $445(15)$ & $.995(-.003)^{\mathrm{a}}$ & $.993(-.005)^{\mathrm{a}}$ & $1.039(-.006)$ & $.010(.004)$ \\
\hline 3 & $542.2^{*}\left(54.1^{* * *}\right)$ & $470(25)$ & $.987(-.008)^{\mathrm{a}}$ & $.983(-.010)^{\mathrm{a}}$ & $1.015(-.024)$ & $.015(.005)$ \\
\hline \multicolumn{7}{|c|}{ Negative events } \\
\hline 1 & $880.3^{* * *}$ & 670 & .986 & .981 & .990 & .022 \\
\hline 2 & $902.9^{* * *}(23.0)$ & $690(20)$ & $.985(-.001)$ & $.982(.001)$ & $.992(.002)$ & $.022(<.001)$ \\
\hline 3 & $1002.8^{* * *}\left(76.3^{* * *}\right)$ & $720(30)$ & $.98 \mathrm{I}(-.004)^{\mathrm{a}}$ & $.977(-.005)^{\mathrm{a}}$ & $.94 I(-.05 I)^{\mathrm{a}}$ & $.025(.003)$ \\
\hline
\end{tabular}

Note. See Supplementary Appendix D for more details on model specifications. Models in bold characters are retained as providing the best fit. ${ }^{*} p<.05,{ }^{* * *} p<.00 \mathrm{I} . \mathrm{I}=$ configural invariance; $2=$ strong invariance (unique thresholds, intercepts, and loadings); $3=$ strict invariance (unique thresholds, intercepts, loadings, and variances). DF = degrees of freedom; CFI = confirmatory fit index; $\mathrm{TLI}=$ Tucker-Lewis index; Mc = McDonald's centrality index; RMSEA = root mean squared error of approximation.

${ }^{\text {a }}$ Evidence of measurement variance: $\triangle \mathrm{CFI}<-.002, \triangle \mathrm{TLI}<-.00 \mathrm{I}, \triangle \mathrm{Mc}<-.007$.

models showed strong invariance, that is, invariance in terms of factor indicators' thresholds, intercepts, and loadings (i.e., $\triangle \mathrm{CFI} \geq-.002, \triangle \mathrm{TLI} \geq-.001, \triangle \mathrm{Mc} \geq-.007$, and $\triangle \mathrm{RMSEA} \leq$ .007 , relative to the configural model; Jorgensen et al., 2018; Sass et al., 2014). This is with the exception of the model for exposure to positive events, which showed evidence of variance across occasions $(\triangle \mathrm{CFI}=-.004$ and $\triangle \mathrm{TLI}=-.006)$ and across gender groups $(\triangle \mathrm{CFI}=-.003$ and $\triangle \mathrm{TLI}=-.005)$. With the latter exceptions, these results provide evidence that the PANALE can be used to compare exposure to stress over time or across groups of adolescents who differ in terms of gender, SES, or dropout status. Finally, we find that the measurement models for exposure to negative stressors also show evidence for strict invariance (i.e., invariance over factor indicators' thresholds, intercepts, loadings, and variances) over time and across SES and dropout groups. The same is true for positive stressors under conditions of strict invariance across SES groups. 
Table 5. Fit Indices (Differences in Fit Indices) of PANALE Models With Increasing Invariance Constraints Across SES Groups.

\begin{tabular}{|c|c|c|c|c|c|c|}
\hline $\begin{array}{l}\text { Invariance } \\
\text { constraints }\end{array}$ & $\chi^{2}\left(\Delta \chi^{2}\right)$ & $\mathrm{DF}(\triangle \mathrm{DF})$ & $\mathrm{CFI}(\triangle \mathrm{CFI})$ & $\mathrm{TLI}(\triangle \mathrm{TLI})$ & $M c(\triangle M c)$ & $\begin{array}{c}\text { RMSEA } \\
(\triangle \mathrm{RMSEA})\end{array}$ \\
\hline \multicolumn{7}{|c|}{ Positive events } \\
\hline I & 436.7 & 430 & .999 & .998 & 1.047 & .005 \\
\hline 2 & 456.1 (19.2) & 445 (I5) & $.998(-.001)$ & $.997(-.001)$ & $1.047(<.001)$ & $.006(.001)$ \\
\hline 3 & $471.2(20.4)$ & 470 (25) & $1.000(.002)$ & $1.000(.003)$ & $1.046(-.001)$ & $.002(-.004)$ \\
\hline \multicolumn{7}{|c|}{ Negative events } \\
\hline 1 & $914.9^{* * *}$ & 670 & .981 & .975 & .968 & .024 \\
\hline 2 & $941.0 * * *(27.1)$ & $690(20)$ & $.980(-.00 \mathrm{I})$ & $.975(<.001)$ & $.969(.001)$ & $.024(<.001)$ \\
\hline 3 & $966.2^{* * *}(36.3)$ & $720(30)$ & $.980(<.001)$ & $.976(.001)$ & $.953(-.016)$ & $.023(-.00 I)$ \\
\hline
\end{tabular}

Note. See Supplementary Appendix D for more details on model specifications. Models in bold characters are retained as providing the best fit. ${ }^{* *} p<.00 \mathrm{I}$. I = configural invariance; 2 = strong invariance (unique thresholds, intercepts, and loadings); $3=$ strict invariance (unique thresholds, intercepts, loadings, and variances). DF = degrees of freedom; CFI = confirmatory fit index; TLI = Tucker-Lewis index; Mc = McDonald's centrality index; RMSEA = root mean squared error of approximation.

Table 6. Fit Indices (Differences in Fit Indices) of PANALE Models With Increasing Invariance Constraints Across Dropout Status Groups.

\begin{tabular}{|c|c|c|c|c|c|c|}
\hline $\begin{array}{l}\text { Invariance } \\
\text { constraints }\end{array}$ & $\chi^{2}\left(\Delta \chi^{2}\right)$ & $\begin{array}{c}\text { DF } \\
(\triangle \mathrm{DF})\end{array}$ & $\mathrm{CFI}(\triangle \mathrm{CFI})$ & $\mathrm{TLI}(\triangle \mathrm{TLI})$ & $M c(\triangle M c)$ & $\begin{array}{c}\text { RMSEA } \\
(\triangle \mathrm{RMSEA})\end{array}$ \\
\hline \multicolumn{7}{|c|}{ Positive events } \\
\hline I & 278.6 & 268 & .997 & .996 & 1.028 & .008 \\
\hline 2 & 292.1 (12.7) & $280(12)$ & $.997(<.001)$ & $.996(<.001)$ & 1.029 (.00I) & $.008(<.00 I)$ \\
\hline 3 & $333.8(25.2)$ & $300(20)$ & $.991(-.006)^{a}$ & $.988(-.008)^{\mathrm{a}}$ & $1.010(-.019)^{\mathrm{a}}$ & $.013(.005)$ \\
\hline \multicolumn{7}{|c|}{ Negative events } \\
\hline I & $853.4^{* * *}$ & 670 & .982 & .977 & .958 & .021 \\
\hline 2 & $879.6 * * *(26.2)$ & $690(20)$ & $.982(<.001)$ & $.977(<.001)$ & $.955(-.003)$ & $.021(<.001)$ \\
\hline 3 & $913.5 * * *(35.5)$ & $720(30)$ & $.981(-.001)$ & $.977(<.001)$ & $.927(-.028)^{\mathrm{a}}$ & $.020(-.001)$ \\
\hline
\end{tabular}

Note. See Supplementary Appendix D for more details on model specifications. Models in bold characters are retained as providing the best fit. ${ }^{\dagger} p<.10,{ }^{* * *} p<.00 \mathrm{I}$. I = configural invariance; 2 = strong invariance (unique thresholds, intercepts, and loadings); 3 = strict invariance (unique thresholds, intercepts, loadings, and variances). DF = degrees of freedom; CFI = confirmatory fit index; TLI = Tucker-Lewis index; $M c=$ McDonald's centrality index; RMSEA = root mean squared error of approximation.

${ }^{\mathrm{a}}$ Evidence of measurement variance: $\triangle \mathrm{CFI}<-.002, \triangle \mathrm{TLI}<-.00 \mathrm{I}, \triangle \mathrm{Mc}<-.007$.

In the models for strict invariance (Supplementary Tables 1 and 2, Supplementary Appendix D), the factor loadings of positive and negative PANALE items were very large and ranged from .572 to .947 , which suggests that the items are good indicators for the latent factors of exposure to stress. This is confirmed by the large internal consistency reported for the PANALE on each measurement occasion, with omega total ranging from .857 to .880 for positive items and from .965 to .976 for negative items (cf. Table 2). Taken together, all the psychometric analyses converge to indicate the scale shows very good construct validity in terms of factorial structure, measurement invariance, and composite reliability.

\section{Criterion Validity With Regard to Distress and Eustress}

As reported in Table 7, the correlational analyses show that the scores for negative stressors are associated positively with indicators of distress (i.e., anxiety, social deviance, dropout intention, 
Table 7. Correlations Between PANALE Scoring Systems (Occurrences vs. Intensity) and Indicators of Stress Responses (Eustress and Distress).

\begin{tabular}{|c|c|c|c|c|c|c|}
\hline \multirow[b]{2}{*}{ Criterion } & \multicolumn{2}{|c|}{ Positive events } & \multirow{2}{*}{$\begin{array}{c}\text { Fisher's test } \\
p<\end{array}$} & \multicolumn{2}{|c|}{ Negative events } & \multirow{2}{*}{$\begin{array}{c}\text { Fisher's tes } \\
p<\end{array}$} \\
\hline & Occurrences & Intensity & & Occurrences & Intensity & \\
\hline \multicolumn{7}{|l|}{ Eustress } \\
\hline Self-esteem & $.230 * * *$ & $.260 * * *$ & .381 & $-\left..39\right|^{* * *}$ & $-.363^{* * *}$ & .370 \\
\hline School liking & $.187^{* * *}$ & $.216^{* * *}$ & .406 &.$-|1| I^{* * *}$ & $-.052^{*}$ & .103 \\
\hline Concentration in class & $.169^{* * *}$ & $.226^{* * *}$ & .103 & $-.209 * * *$ & $-.143^{* * *}$ & .061 \\
\hline Grades & $.053 \dagger$ & $.075^{* *}$ & .544 & $-.142^{* * *}$ & $-.147^{* * *}$ & .888 \\
\hline \multicolumn{7}{|l|}{ Distress } \\
\hline Anxiety & $-.053^{* *}$ & $-.059 * *$ & .869 & $.41 I^{* * *}$ & $.438^{* * *}$ & .366 \\
\hline Social deviance & -.010 & -.015 & .891 & $.498 * * *$ & $.516 * * *$ & .506 \\
\hline Dropout intention & $-.038 \dagger$ & $-.074^{* * *}$ & .321 & $.292^{* * *}$ & $.296 * * *$ & .904 \\
\hline Misbehavior at school & .002 & -.002 & .913 & $.477^{* * *}$ & $.507^{* * *}$ & .277 \\
\hline Absences $(\log +\mathrm{I})$ & $-.05 I^{*}$ & $-.047^{*}$ & .912 & $.144^{* * *}$ & $.149 * * *$ & .888 \\
\hline
\end{tabular}

Note. $n=1512$ high school students. ${ }^{\dagger} p<.10,{ }^{*} p<.05,{ }^{* *} p<.01,{ }^{* * *} p<.001$.

misbehavior at school, and school absenteeism; .144 $\leq r \leq .498)$ and negatively with indicators of eustress (i.e., self-esteem, school liking, concentration in class, and grades; $-.111 \geq r \geq-.391$ ). These associations are larger than those reported for existing stressors scales (i.e., $.17<r_{\text {median }}<$ .38 for distress, $-.07>r_{\text {median }}>-.17$ for eustress; Núñez-Regueiro et al., in press). Conversely, scores for positive stressors correlated positively with indicators of eustress $(.053 \leq r \leq .230)$ and negatively with three indicators of distress (i.e., anxiety, dropout intention, and absences; $-.038 \geq$ $r \geq-.051$ ). Table 7 also reports the correlations based on the second rating system of the PANALE, namely, intensity. As expected, the non-significant Fisher tests suggest that the two rating systems (i.e., occurrences vs. intensity) do not differ in their criterion validity.

\section{Discussion}

The present article developed and validated a short scale measuring adolescent positive and negative stressors (PANALE). Our analyses show that this scale has good psychometric qualities in terms of content validity (i.e., coverage of adolescent stressors), construct validity (i.e., factorial structure, measurement invariance, and internal consistency), and criterion validity (i.e., associations with eustress and distress), in a way that outperforms existing scales while overcoming their limitations in terms of costs, feasibility, and construct validity. Aligning with the literature, we find that exposure to negative events was more strongly and more systematically related with stress responses than exposure to positive events (Kanner et al., 1987; Masten et al., 1994; Newcomb et al., 1981; Swearingen \& Cohen, 1985). Also, results give support to the notion that stress scores can be computed based on total occurrences of stressors (vs. total intensities) without loss of concurrent validity (Núñez-Regueiro et al., in press).

To date, the PANALE is the first stressors scale to have been proofed for measurement invariance over time and across subgroups of adolescents. More precisely, the exposure to positive stressors scale was shown to be strongly invariant across SES and dropout status groups. The model invariance over time and across gender groups also showed excellent fit to the data, although variance was observed in certain parameters (i.e., in thresholds, loadings, or intercepts). Studies willing to test developmental or gender differences in the exposure to positive events can consider the PANALE as an appropriate tool but should be aware of possible variance in the underlying measurement models over time or over male and female adolescents. Moreover, the 
PANALE exposure to negative stressors scale was shown to be strongly or strictly invariant across five measurements and across groups of adolescents defined by gender, parental SES, and dropout status. It can thus be recognized as a valid tool to assess group differences in exposure to negative or positive stressors (at least for groups defined by parental SES or dropout status) or to analyze the development of exposure to negative stressors over time and its impact on academic achievement or graduation.

The present study also showed evidence for criterion validity with regard to eustress and distress symptoms, suggesting that the PANALE can be used to analyze the effects of stress exposure on adolescent development (e.g., self-esteem, anxiety, and social deviance) and school adaptation (e.g., school liking, concentration in class, grades, dropout intention, misbehavior at school, and absences). Results also suggest that a simple scoring system based on occurrences of events (Yes/No) is as efficient as more complex ones (e.g., with appraisals of intensity of stressors) and can be used without loss of generality. Given its multidimensional criterion validity and its ease of use (i.e., only 11 items coded on a Yes/No rating system), it would be interesting in future research to validate the PANALE for its use as a pre-diagnostic tool to identify students at risk of psychological distress or school failure. In this perspective, future studies should evaluate the extent to which this instrument can correctly identify students clinically at-risk (vs. not clinically at-risk) by using dedicated techniques such as receiver operating characteristic analysis (Archambault \& Janosz, 2009; Fawcett, 2006).

Complementary research is needed to address certain limitations of this study. For instance, although the PANALE was shown to be valid in the present French sample, future studies are warranted to confirm its psychometric qualities in other national contexts or among younger adolescents (e.g., in middle school). In this respect, a recent meta-analysis has shown that the events covered by the PANALE items are also commonly found in Western countries other than France (e.g., Australia, Canada, Netherlands, United Kingdom, and United States of America; Authors, n.d.b), but the importance or meaning of these events might differ for adolescents living in other countries with different economies or lifestyles. Moreover, the development of the scale did not consider gender differences in the experience of adolescent stressors. This approach enabled obtaining a scale that allows for quantitative differences in the exposure to stressors between male and female adolescents, but it also overlooked qualitative differences in their life experiences. To address this issue, studies using the PANALE might consider complementing their quantitative analysis with techniques for qualitative analysis (e.g., semi-structured interviews, observations, and content analysis of autobiographical texts) to shed light on these differences, thus obtaining more qualified results on the role of stressors during adolescence.

Notwithstanding these limitations, the present study has shown that the PANALE scale constitutes a sound alternative to existing methods (e.g., intensive checklists or interviews) for measuring adolescent stress processes at school or in other contexts of scientific interest.

\section{Acknowledgments}

Thanks are due to the headmasters, school counselors, and teachers for their collaboration and help in the surveying process.

\section{Declaration of Conflicting Interests}

The author(s) declared no potential conflicts of interest with respect to the research, authorship, and/or publication of this article.

\section{Funding}

The author(s) disclosed receipt of the following financial support for the research, authorship, and/or publication of this article: This research was supported partly by a doctoral grant to the first author (Appel à projets Grenoble Innovation Recherche, "DESCOL") and by the Regional Board of Education of Grenoble. 


\section{ORCID iD}

Fernando Núñez-Regueiro (1) https://orcid.org/0000-0003-4784-2021

\section{Supplemental material}

Supplemental material for this article is available online.

\section{References}

Aldwin, C. M. (2007). Stress, coping, and development: An integrative perspective (2nd ed., Vol. XVI). Guilford Press.

Archambault, I., \& Janosz, M. (2009). Fidélité, validité discriminante et prédictive de l'indice de prédiction du décrochage. Canadian Journal of Behavioural Science/Revue Canadienne Des Sciences Du Comportement, 41(3), 187-191. doi:10.1037/a0015261

Bandalos, D. L. (2014). Relative performance of categorical diagonally weighted least squares and robust maximum likelihood estimation. Structural Equation Modeling: A Multidisciplinary Journal, 21(1), 102-116. doi:10.1080/10705511.2014.859510

Berden, G. F. M. G., Althaus, M., \& Verhulst, F. C. (1990). Major life events and changes in the behavioural functioning of children. Journal of Child Psychology and Psychiatry, 31(6), 949-959. doi:10.1111/j. 1469-7610.1990.tb00836.x

Bobo, J. K., Gilchrist, L. D., Elmer, J. F., Snow, W. H., \& Schinke, S. P. (1986). Hassles, role strain, and peer relations in young adolescents. The Journal of Early Adolescence, 6(4), 339-352. doi:10.1177/ 0272431686064005

Brown, T. A. (2015). Confirmatory factor analysis for applied research. Guilford Publications

Cheng, S.-T., \& Li, K.-K. (2010). Combining major life events and recurrent hassles in the assessment of stress in Chinese adolescents: Preliminary evidence. Psychological Assessment, 22(3), 532-538. doi:10. 1037/a0019579

Compas, B. E. (1987). Stress and life events during childhood and adolescence. Clinical Psychology Review, 7(3), 275-302. doi:10.1016/0272-7358(87)90037-7

Compas, B. E., Davis, G. E., Forsythe, C. J., \& Wagner, B. M. (1987). Assessment of major and daily stressful events during adolescence: The Adolescent Perceived Events Scale. Journal of Consulting and Clinical Psychology, 55(4), 534. doi:10.1037/0022-006X.55.4.534

Dupéré, V., Dion, E., Harkness, K., McCabe, J., Thouin, É., \& Parent, S. (2017). Adaptation and validation of the Life Events and Difficulties Schedule for use with high school dropouts. Journal of Research on Adolescence, 27(3), 683-689. doi:10.1111/jora.12296

Dupéré, V., Dion, E., Leventhal, T., Archambault, I., Crosnoe, R., \& Janosz, M. (2018). High school dropout in proximal context: The triggering role of stressful life events. Child Development, 89(2), e107-e122. doi:10.1111/cdev.12792.

Dupéré, V., Leventhal, T., Dion, E., Crosnoe, R., Archambault, I., \& Janosz, M. (2015). Stressors and turning points in high school and dropout: A stress process, life course framework. Review of Educational Research, 85(4), 591-629. doi:10.3102/0034654314559845.

Fabrigar, L. R., Wegener, D. T., MacCallum, R. C., \& Strahan, E. J. (1999). Evaluating the use of exploratory factor analysis in psychological research. Psychological Methods, 4(3), 272-299. doi:10.1037/1082989X.4.3.272

Fawcett, T. (2006). An introduction to ROC analysis. Pattern Recognition Letters, 27(8), 861-874. doi:10. 1016/j.patrec.2005.10.010

Finn, J. D., Fish, R. M., \& Scott, L. A. (2008). Educational sequelae of high school misbehavior. The Journal of Educational Research, 101(5), 259-274. doi:10.3200/JOER.101.5.259-274

French, B. F., \& Finch, W. H. (2006). Confirmatory factor analytic procedures for the determination of measurement invariance. Structural Equation Modeling: A Multidisciplinary Journal, 13(3), 378-402. doi:10.1207/s15328007sem1303_3

Galesic, M., \& Bosnjak, M. (2009). Effects of questionnaire length on participation and indicators of response quality in a web survey. Public Opinion Quarterly, 73(2), 349-360. doi:10.1093/poq/nfp031 
Garrido, L. E., Abad, F. J., \& Ponsoda, V. (2011). Performance of Velicer's Minimum Average Partial factor retention method with categorical variables. Educational and Psychological Measurement, 71(3), 551-570. doi:10.1177/0013164410389489

Garrido, L. E., Abad, F. J., \& Ponsoda, V. (2013). A new look at Horn's parallel analysis with ordinal variables. Psychological Methods, 18(4), 454-474. doi:10.1037/a0030005

Garrido, L. E., Abad, F. J., \& Ponsoda, V. (2016). Are fit indices really fit to estimate the number of factors with categorical variables? Some cautionary findings via Monte Carlo simulation. Psychological Methods, 21(1), 93-111. doi:10.1037/met0000064

Gibson, A. M., \& Bowling, N. A. (2020). The effects of questionnaire length and behavioral consequences on careless responding. European Journal of Psychological Assessment, 36(2), 410-420. doi:10.1027/ $1015-5759 / \mathrm{a} 000526$

Graham, J. W. (2003). Adding missing-data-relevant variables to FIML-based structural equation models. Structural Equation Modeling, 10(1), 80-100. doi:10.1207/S15328007SEM1001_4

Grant, K. E., Compas, B. E., Thurm, A. E., McMahon, S. D., \& Gipson, P. Y. (2004). Stressors and child and adolescent psychopathology: Measurement issues and prospective effects. Journal of Clinical Child and Adolescent Psychology, 33(2), 412-425. doi:10.1207/s15374424jccp3302_23

Green, S. B., Akey, T. M., Fleming, K. K., Hershberger, S. L., \& Marquis, J. G. (1997). Effect of the number of scale points on chi-square fit indices in confirmatory factor analysis. Structural Equation Modeling: A Multidisciplinary Journal, 4(2), 108-120. doi:10.1080/10705519709540064

Hallquist, M. N., \& Wiley, J. F. (2018). MplusAutomation: An R package for facilitating large-scale latent variable analyses in M plus. Structural Equation Modeling: A Multidisciplinary Journal, 25(4), 621-638. doi:10.1080/10705511.2017.1402334

Harter, S. (1988). Manual for the self-perception profile for adolescents. University of Denver

Janosz, M., Archambault, I., Lacroix, M., \& Lévesque, J. (2007). Trousse d'évaluation des décrocheurs potentiels (TEDP): Manuel d'utilisation. Montréal. Groupe de recherche sur les environnements scolaires, Université de Montréal.

Jorgensen, T. D., Kite, B. A., Chen, P.-Y., \& Short, S. D. (2018). Permutation randomization methods for testing measurement equivalence and detecting differential item functioning in multiple-group confirmatory factor analysis. Psychological Methods, 23(4), 708-728. doi:10.1037/met0000152

Kanner, A. D., Feldman, S. S., Weinberger, D. A., \& Ford, M. E. (1987). Uplifts, hassles, and adaptational outcomes in early adolescents. The Journal of Early Adolescence, 7(4), 371-394. doi:10.1177/ 0272431687074002

Kite, B. A., Jorgensen, T. D., \& Chen, P.-Y. (2018). Random permutation testing applied to measurement invariance testing with ordered-categorical indicators. Structural Equation Modeling: A Multidisciplinary Journal, 25(4), 573-587. doi:10.1080/10705511.2017.1421467

Kohn, P. M., \& Milrose, J. A. (1993). The inventory of high-school students' recent life experiences: A decontaminated measure of adolescents' hassles. Journal of Youth and Adolescence, 22(1), 43-55. doi: 10.1007/BF01537903

Lewinsohn, P. M., Rohde, P., \& Gau, J. M. (2003). Comparability of self-report checklist and interview data in the assessment of stressful life events in young adults. Psychological Reports, 93(2), 459-471. doi:10. 2466/pr0.2003.93.2.459

Masten, A. S., Neemann, J., \& Andenas, S. (1994). Life events and adjustment in adolescents: The significance of event independence, desirability, and chronicity. Journal of Research on Adolescence, 4(1), 71-97. doi:10.1207/s15327795jra0401_5

McNeish, D. (2018). Thanks coefficient alpha, we'll take it from here. Psychological Methods, 23(3), 412-433. doi:10.1037/met0000144

Muthén, L., \& Muthén, B. (2012). Mplus Version 7.1 user's guide. Muthén \& Muthén

Newcomb, M. D., Huba, G. J., \& Bentler, P. M. (1981). A multidimensional assessment of stressful life events among adolescents: Derivation and correlates. Journal of Health and Social Behavior, 22(4), 400-415. doi: $10.2307 / 2136681$

Núñez-Regueiro, F., Archambault, I., Bressoux, P., \& Nurra, C. (in press). Measuring stressors among children and adolescents: A scoping review 1956-2020. Adolescent Research Review.

Núñez-Regueiro, F., \& Núñez-Regueiro, S. (2021). Identifying salient stressors of adolescence: A metaanalysis and a content analysis. Manuscript submitted for publication. 
Pearlin, L. I., \& Bierman, A. (2013). Current issues and future directions in research into the stress process. In C. S. Aneshensel, J. C. Phelan, \& A. Bierman (Eds.), Handbook of the Sociology of Mental Health (pp. 325-340). Springer Netherlands

$\mathrm{R}$ Core Team. (2016). $R$ : A language and environment for statistical computing (3.6) [Computer software]. $\mathrm{R}$ Foundations for Statistical Computing. https://www.R-project.org

Revelle, W. (2019). psych: Procedures for personality and psychological research (1.9.12) [R package]. Northwestern University. https://CRAN.R-project.org/package=psych

Rhemtulla, M., Brosseau-Liard, P. É., \& Savalei, V. (2012). When can categorical variables be treated as continuous? A comparison of robust continuous and categorical SEM estimation methods under suboptimal conditions. Psychological Methods, 17(3), 354-373. doi:10.1037/a0029315

Rosseel, Y. (2012). Lavaan: An R package for structural equation modeling and more. Version 0.5-12 (BETA). Journal of Statistical Software, 48(2), 1-36

Sarason, I. G., Johnson, J. H., \& Siegel, J. M. (1978). Assessing the impact of life changes: Development of the Life Experiences Survey. Journal of Consulting and Clinical Psychology, 46(5), 932-946. doi:10. 1037/0022-006X.46.5.932

Sass, D. A., Schmitt, T. A., \& Marsh, H. W. (2014). Evaluating model fit with ordered categorical data within a measurement invariance framework: A comparison of estimators. Structural Equation Modeling, 21(2), 167-180. doi:10.1080/10705511.2014.882658

Skinner, E. A., Kindermann, T. A., \& Furrer, C. J. (2008). A motivational perspective on engagement and disaffection: Conceptualization and assessment of children's behavioral and emotional participation in academic activities in the classroom. Educational and Psychological Measurement, 69(3), 493-525. doi: $10.1177 / 0013164408323233$

Swearingen, E. M., \& Cohen, L. H. (1985). Measurement of adolescents' life events: The junior high life experiences survey. American Journal of Community Psychology, 13(1), 69-85. doi:10.1007/BF00923260

Turner, R. J., \& Wheaton, B. (1997). Checklist measurement of stressful life events. In S. Cohen, R. C. Kessler, \& Lynn U. Gordon (Eds.), Measuring stress: A guide for health and social scientists (pp. 29-58). Oxford University Press

Untas, A., Aguirrezabal, M., Chauveau, P., Leguen, E., Combe, C., \& Rascle, N. (2009). Anxiété et dépression en hémodialyse: Validation de l'Hospital Anxiety and Depression Scale (HADS). Néphrologie \& Thérapeutique, 5(3), 193-200. doi:10.1016/j.nephro.2009.01.007

Vandenberg, R. J., \& Lance, C. E. (2000). A review and synthesis of the measurement invariance literature: Suggestions, practices, and recommendations for organizational research. Organizational Research Methods, 3(1), 4-69. doi:10.1177/109442810031002

Wagner, C., Abela, J. R., \& Brozina, K. (2006). A comparison of stress measures in children and adolescents: A self-report checklist versus an objectively rated interview. Journal of Psychopathology and Behavioral Assessment, 28(4), 250-260. doi:10.1007/s10862-005-9010-9

Wheaton, B., Young, M., Montazer, S., \& Stuart-Lahman, K. (2013). Social stress in the twenty-first century. In C. S. Aneshensel, J. C. Phelan, \& A. Bierman (Eds.), Handbook of the Sociology of Mental Health (pp. 299-323). Springer Netherlands

Williamson, D. E., Birmaher, B., Ryan, N. D., Shiffrin, T. P., Lusky, J. A., Protopapa, J., Dahl, R. E., \& Brent, D. A. (2003). The stressful life events schedule for children and adolescents: Development and validation. Psychiatry Research, 119(3), 225-241. doi:10.1016/S0165-1781(03)00134-3

Wu, H., \& Estabrook, R. (2016). Identification of confirmatory factor analysis models of different levels of invariance for ordered categorical outcomes. Psychometrika, 81(4), 1014-1045. doi:10.1007/s11336016-9506-0

Wu, K. K., \& Lam, D. J. (1993). The relationship between daily stress and health: Replicating and extending previous findings. Psychology \& Health, 8(5), 329-344. doi:10.1080/08870449308401926 